\title{
Operational Performance of a Combined TLP-type Floating Wind Turbine and Heave-type Floating Wave Energy Converter System
}

\author{
Meng-ran ZHOU \\ Deepwater Engineering Research Center, Dalian \\ University of Technology \\ Dalian, China, 116024 \\ zmrduters@163.com
}

\author{
Nian-xin REN ${ }^{*}$ \\ Deepwater Engineering Research Center, Dalian \\ University of Technology \\ Dalian, China, 116024 \\ Corresponding author: rennianxin@dlut.edu.cn
}

\author{
Ying PAN \\ Engineering Company Ltd. of CCCC First Harbor \\ Engineering Company Ltd, \\ Dalian, China, 116000 \\ panying0202@163.com
}

Ying ZHU

Deepwater Engineering Research Center, Dalian

University of Technology

Dalian, China, 116024

zhuyingax@163.com

\begin{abstract}
This paper deals with a novel concept by combining a tension leg platform -type floating wind turbine and a heavetype wave energy converter that is referred as the 'TWWC' (TLP-WT-WEC- Combination) system herein. Concept feasibility study has been carried out by using numerical simulations in the time domain. Hydrodynamic loads of the TLP and the WEC are calculated by the AQWA code, which is available for modeling multi-body systems including both mechanical and hydrodynamic couplings between the TLP and the WEC. The aerodynamic loads of the wind turbine are simplified as the thrust -wind speed fitting function based on the design data of NREL 5MW wind turbine with the consideration of the real-time motion of the TLP. Firstly, the effects of different power-take-off (PTO) parameters and wave periods on the performance of the WEC's wave energy production under typical wave cases have been investigated, and a preliminary optimal value for the PTO's damping stiffness has been proposed. Secondly, the main dynamic characteristic of the TWWC system under typical operational sea cases was investigated by using coupled wind-wave loads analysis. Finally, the maximum operational performance of the TWWC system under typical coupled wind and irregular sea case has been clarified, and the possible maximum transient wave power and maximum PTO's damping force have been obtained, which are very helpful for the optimal design of the PTO system
\end{abstract}

Keywords- combined wind and wave power system; tension leg platform; power take off system; dynamic response

\section{INTRODUCTION}

Offshore wind is steadier and stronger than onshore wind, which is an important source of renewable energy. Offshore areas not only have strong winds but also contain all kinds of potential renewable energy sources, such as ocean waves and tidal currents. Therefore, it is necessary to investigate the possibility of utilizing these energy potentials simultaneously. In deep water with a depth of more than $60 \mathrm{~m}$, wind turbines are suggested to be supported by floating platform from a cost-benefit point of view[1]. Due to natural correlation, ocean wave energy may also be considerable where the offshore wind energy resource is rich, the combined concept of floating wind turbine (FWT) and wave energy converter (WEC) systems makes it possible to utilize both energy simultaneously. The combined concept not only sharing the same supporting structure system and cables in the view of cost reduction, but also utilizing the area of the ocean more efficiently. Some efforts devoted into the combination of FWT and WEC have been practised and reported by previous researchers. combining an oscillating water column type WEC and a point-absorber-type WEC with a semisubmersible type floating wind turbine (FWT) 'WindFloat' has been proposed using both numerical and laboratory models[2-3].A $5 \mathrm{MW}$ WT and three point absorber WECs with a single column tension leg platform consist of a combined concept that has been studied, and its main dynamic responses have been obtained for both operational and extreme sea conditions by the coupled tool Simo-RiflexAerodyn in the time domain[4].Another combined concept that a combined semi-submersible wind turbine and rotating flap type wave energy converters (SFC) system has been investigated [5], it was found that the rotating flaps could result in an increase of the power production without significantly affecting the behavior of the semi-submersible platform. In addition, other combined concepts was also proposed, such as the combination of a spar-type FWT and a torus-shaped point absorber-type WEC which was denoted as the STC [6], The dynamic response and power performance of the combined concept under operational conditions has been studied. It was showed that the STC system could increase total power production compared to the segregated FWT concepts [7-8]. The possible slamming and green water effects of the STC system have been in laboratory tests, a 1:50 scaling ratio model test of the STC system under operational conditions was performed to assess the performance of the concept, two survival modes tests (fixed model and submerged model) were proposed to 
investigate the performance of the STC in extreme conditions [9-11].what is more, the long-term performance in terms of annual power production, structural fatigue damage, and extreme responses of the STC system has been further investigated using coupled wind-wave time-domain analysis with the consideration of effect of different survival conditions[12-13].So far, there is limited information about the conceptual design of the combined WT and WEC nearshore systems with the fixed -bottom foundation.

In the present study, a combined concept involving a combination of a tension leg platform -type floating wind turbine and a heave-type wave energy converter (WEC) is considered, which is referred as the 'TWWC' (TLP-WTWEC Combination) system herein. The effect of different PTO parameters and wave periods on the performance of the WEC's wave energy production under typical wave cases has been investigated. In addition, the main dynamic characteristics of the TWWC system, typical operational coupled wind-wave sea cases have been clarified by using coupled wind and wave numerical simulation in the timedomain.

\section{NUMERICAL MODEL OF THE TWWC SYSTEM}

\section{A. Description of the Tension Leg Platform WT and WEC Combination Systems}

The concept that combine the tension leg platform with heave-type WEC is inspired by both the floating STC system developed by NTNU[6] and the two-body axi-symmetric floating WEC 'Wavebob'[14] developed in Ireland. The present TWWC system is illustrated in Fig.1, and the main design parameters are list in Table I. In this concept, The WEC slides along the TLP to extract energy by the relative heave motions through a power take off (PTO) system from waves while the NREL $5 \mathrm{MW}$ wind turbine generates power from the wind[15]. The connection between the TLP and the WEC should allow the system to move freely in heave but let the two bodies move together in other directions.

\section{B. The Numerical Modeling of the TWWC System}

The TWWC system is modelled as two rigid bodies, a TLP FWT and a WEC, pulley-slide system at their interfaces to connect them. Hydrodynamic properties of two rigid bodies involved in the TWWC, including their coupling interactions, and the coupled wave- and wind-induced responses have been obtained using AQWA code [16] in the time domain, which is flexible for model multi-body systems and can accommodate the introduction of both mechanical and hydrodynamic couplings between the bodies. The hydrodynamic panel model is shown in Fig.2. The aerodynamic loads on both the wind turbine rotor and the tower are simplified as the external force based on the design data of the NREL 5MW wind turbine[15], which is shown in Fig.3.

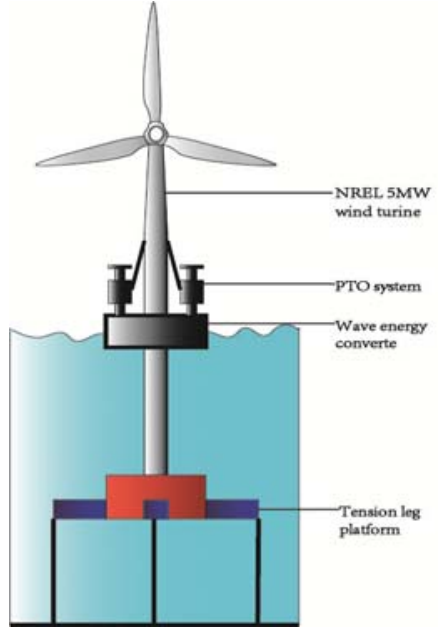

Figure 1. Conceptual sketch of the TWWC system

TABLE I. The Main Design Parameters For The TWWC System

\begin{tabular}{ll}
\hline Parameters & Value \\
\hline Wind turbine & NREL 5MW \\
Hub and Nacelle mass & $350 \mathrm{t}$ \\
Tower height/mass & $90 \mathrm{~m} / 345 \mathrm{t}$ \\
Tower diameter at SWL & $6.5 \mathrm{~m}$ \\
Tower height under water & $20 \mathrm{~m}$ \\
TLP platform & \\
Floater diameter and height & $20 \mathrm{~m} ; 10 \mathrm{~m}$ \\
Outrigger length & $20 \mathrm{~m}$ \\
Outrigger cross sectional area & $4 \mathrm{~m} * 4 \mathrm{~m}=16 \mathrm{~m}^{2}$ \\
Water depth & $100 \mathrm{~m}$ \\
WEC device & \\
Outer/inner diameter & $20 \mathrm{~m} / 8 \mathrm{~m}$ \\
Height/ draft & $8 \mathrm{~m} / 3 \mathrm{~m}$ \\
Displacement & $791.6 \mathrm{~m}^{3}$ \\
Center of mass & $(0,0,-1 \mathrm{~m})$ \\
\hline
\end{tabular}

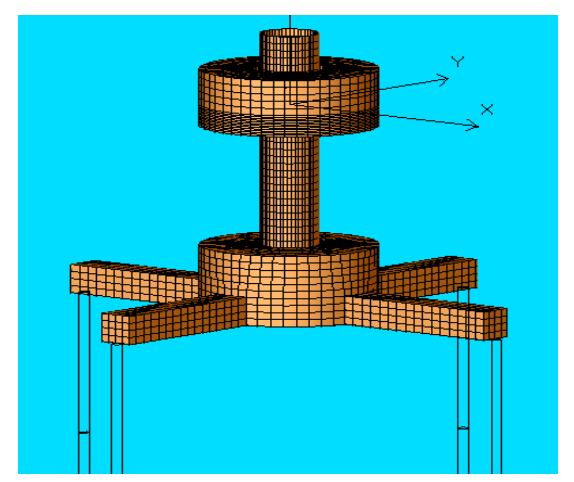

Figure 2. Panel models for the hydrodynamic analysis 


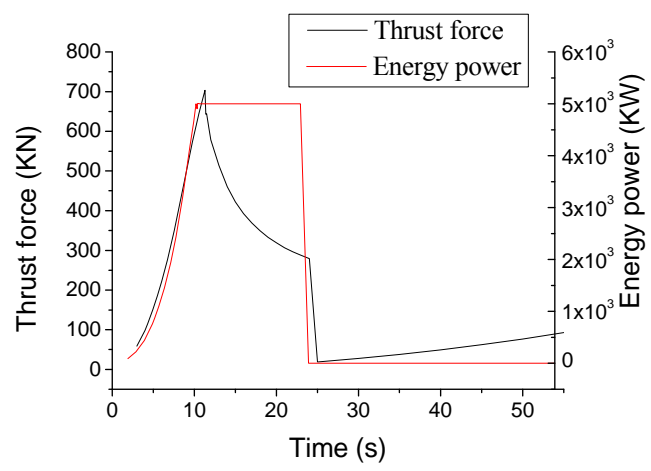

Figure 3. Design that uses of the thrust force and wind power of the NREL $5 \mathrm{MW}$ wind turbine

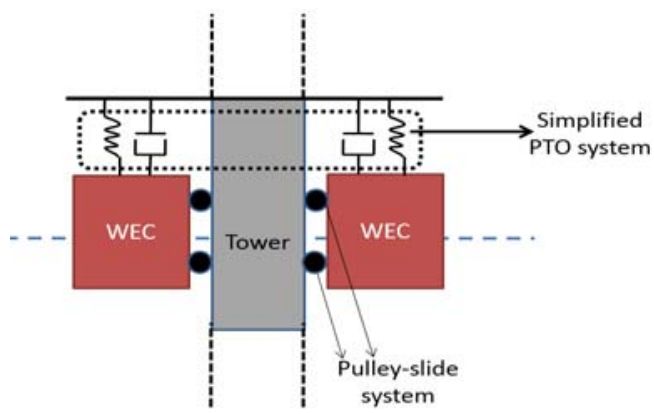

Figure 4. Simplified dynamic coupling model between the WEC and tower

The Power take-off (PTO) system, to absorb wave power from the relative heave motion between the TLP and the WEC, which is modelled as heave-direction linear dampers (Bpto) and linear springs (Kpto) between the TLP and the WEC bodies (as shown in Fig.4). The dampers and springs are simplified corresponding fender features in AQWA code. This system implies that the wave power captured by the WEC can be simply estimated with the PTO damping force and the relative heave velocity between the two bodies, the PTO damping force is proportional to the relative velocity and BPTO.

\section{NUMERICAL RESULTS}

\section{A. Effect of Different Bpto Coefficients on the Performance of the WEC}

Considering the performance of the WEC can been strongly affected by different Bpto parameters, it is necessary to optimize the Bpto coefficients for the preliminary design of the TWWC system. The results of the mean wave power of the WEC under the wave height of $2 \mathrm{~m}$ with the wave period of 10s are shown in Fig.5. From Fig.5, it can be observed that the mean wave power increase with the increasing of the Bpto when Bpto is less than 3.0 $\mathrm{MNs} / \mathrm{m}$, while decrease as the Bpto increases when Bpto is larger than $3.0 \mathrm{MNs} / \mathrm{m}$. The maximum transient wave power $(222.5 \mathrm{KW})$ occurred when BPTO is $3.0 \mathrm{MNs} / \mathrm{m}$. Therefore, the preliminary optimal value of the Bpto coefficient for the TWWC system can be selected as 3.0 $\mathrm{MNs} / \mathrm{m}$.

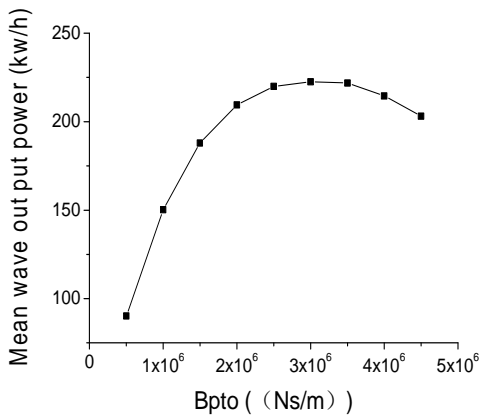

Figure 5. Performance of the WEC under different Bpto coefficients

The effect of different wave periods $(\mathrm{H}=2 \mathrm{~m}, \mathrm{Bpto}=3.0$ $\mathrm{MNs} / \mathrm{m}$ )on the WEC's wave energy production has also been investigated. the optimized results are shown in Fig.6. From Fig.6, it is easy to draw the conclusion that the optimal wave period for the wave power production of the TWWC system is around 10s, which depends on the draft (weight) of the WEC device, outer diameter of the WEC, as well as the Bpto parameter. Therefore, according to different local sea conditions, the optimal wave period of the TWWC system should be adjusted by changing the three mentioned parameters comprehensively.

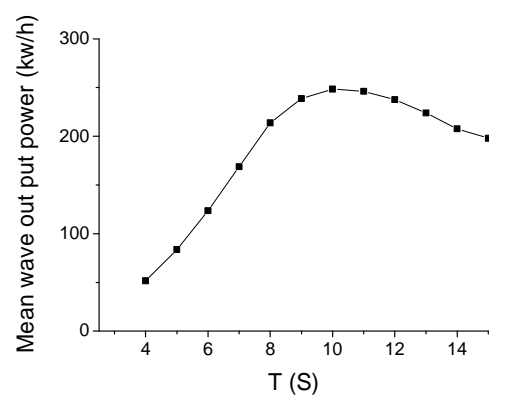

Figure 6. Performance of the WEC under different wave periods

\section{B. Typical Coupled Wind and Regular Wave Sea Case}

Considering the rated wind case is an important load case for the wind turbine, The typical conditions was selected as the coupled rated wind speed $(11.4 \mathrm{~m} / \mathrm{s})$ and corresponding regular wave sea case $(\mathrm{H}=3 \mathrm{~m} \mathrm{~T}=10 \mathrm{~s})$, The surge velocity responses of TLP, wave output power, wind output power and the tension of the most loaded tether have been for the TWWC system, and the main results are shown in Fig $7 \mathrm{a} \sim \mathrm{c}$, respectively.

From Fig.7a, it can be observed the range of surge velocity of TLP, which should be considered when computing the relative wind speed .Fig. $7 \mathrm{~b}$ indicates that the wave output power is much smaller than the rated wind output power, the power production of WT will keep constant $(5 \mathrm{MW})$ when the relative wind speed above rated wind speed $(11.4 \mathrm{~m} / \mathrm{s})$ due to the application of WT control system, Therefore, the wind output power plays an important 
role under the rated wind sea case. From Fig.7c, it can be observed that the wave load play a dominate role in both the fluctuation and the magnitude responses of the tether force, while the aerodynamic loads can affect the mean tether force.

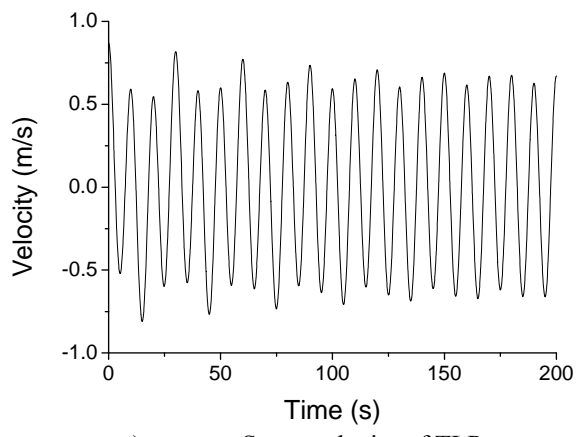

a)

Surge velocity of TLP

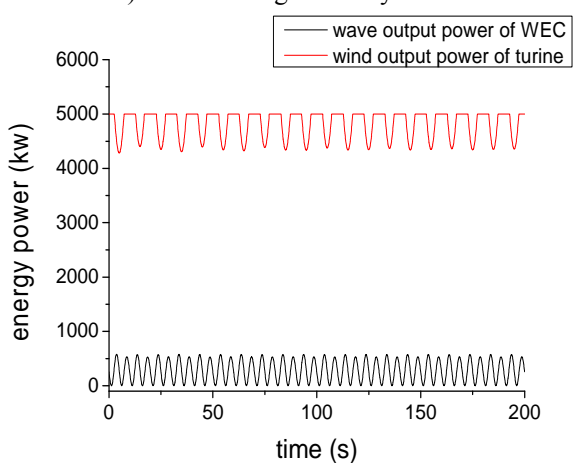

b)

Wave and wind output power of the TWWC system

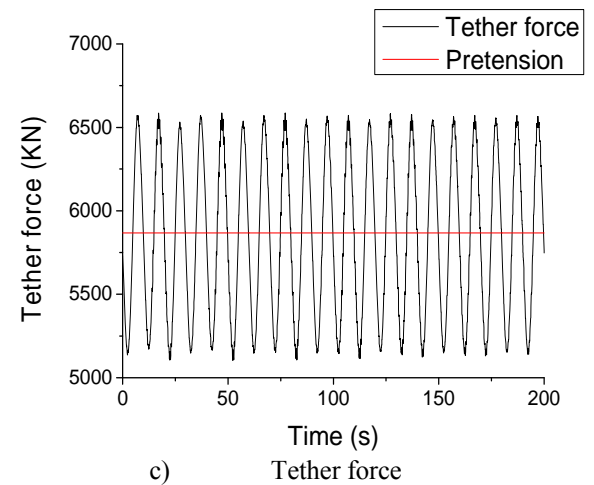

Figure 7. Main dynamic responses of the TWWC system under rated wind sea case.

\section{Typical Maximum Operational Sea Case}

To ensure the reliability and safety of the combined system under the real sea condition, the maximum operational performance of the TWWC system should be investigated. The JONSWAP spectra with a default peak parameter $\gamma$ value of 3.3 is used to describe the characters of the irregualr wave with the significant wave height $(\mathrm{Hs})$ of $6 \mathrm{~m}$ (maximum WT operational Hs) and spectral peak period (Tp) of $10 \mathrm{~s}$. The wind speed is assumed to be $24 \mathrm{~m} / \mathrm{s}$ (maximum WT operational wind speed). The numerical simulation of the TWWC system under the coupled wind and irregular wave sea case was performed, and the main results are shown in Fig. 8

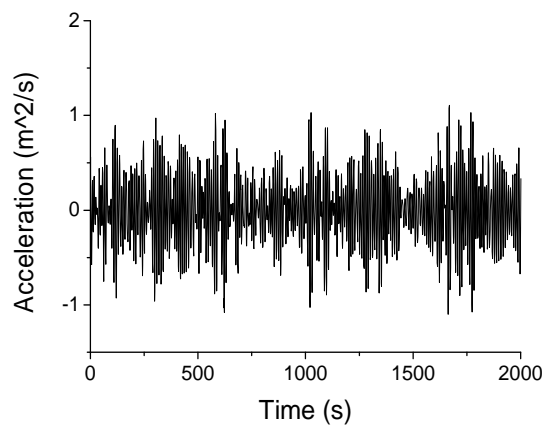

a)

Nacelle's acceleration

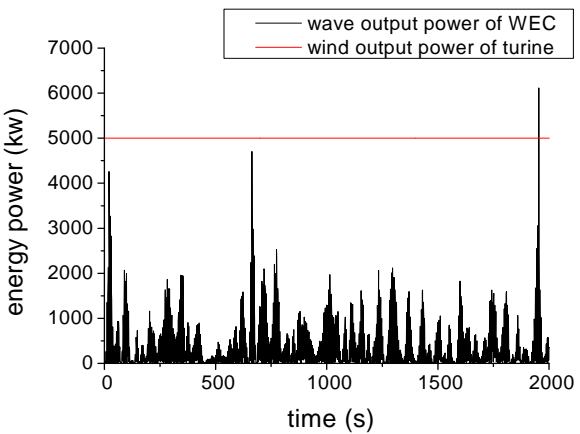

b)

Wave and wind output power of the TWWC system

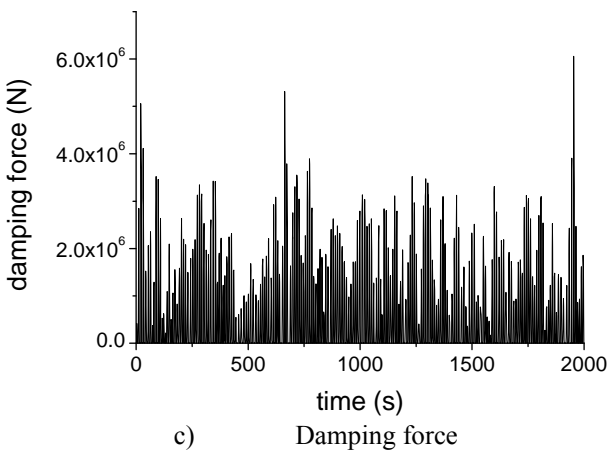

Figure 8. Main responses of the TWWC system

From Fig. $8 \mathrm{a}$, it can be seen that the nacelle's acceleration ranges from $-1 \mathrm{~m} / \mathrm{s}^{2}$ to $1 \mathrm{~m} / \mathrm{s}^{2}$, the maximum nacelle's acceleration will have a negative effect on the security of the WT mechanical transmission system and result in consideration inertial force acting on the top tower, which will be a great challenge to design the TWWC system under the maximum operational cases. From Fig.8b, it can be seen that the maximum transient wave energy power produced by the PTO system can be more than 6MW, with more significant fluctuation than the wind power, which will be a challenge for the safety of the PTO system to withstand such a power load. The Fig.8c, it can be seen that the maximum PTO's damping force can reach more than $6 \mathrm{MN}$ with significant fluctuation, which will induce considerable internal loads acting on the PTO system. 


\section{CONCLUSIONS}

In this paper, a combination of TLP-type FWT and a heave-type wave energy converter referred as TWWC system was proposed and the dynamic response characteristics of the TWWC system under typical operational sea cases have been investigated using AQWA code. The main results can be summarized as follows:

The preliminary optimal value of the Bpto parameter for the TWWC's PTO system has been proposed to be 3.0 $\mathrm{MNs} / \mathrm{m}$, and the related optimal wave period of the TWWC system is around $10 \mathrm{~s}$, which depends on the draft (weight) of the WEC, outer diameter of the WEC, as well as the Bpto parameter.

For the normal operational sea condition, the wave output power is much smaller than the power produced, while the fluctuation of the wave power is much significant than that of wind power.

The maximum instantaneous wave power production from the WEC can exceed the rated wind power, while the wind power production play a dominate role in the combined system. In addition, the maximum responses of the PTO's damping force and the nacelle's acceleration may be challenging for the optimal and ULS design of the TWWC system, some optimal operational strategies should be considered to improve the performance of the TWWC system.

\section{FUTURE WORK}

The present study focuses on the feasibility of a novel concept by combining a TLP-type FWT and heave-type wave energy converter to produce power. Many challenges still remain related to the feasibility of the TWWC, and development of a robust concept for actual deployment requires further investigation. The challenges will include the long-term fatigue/extreme analysis, survival strategies, model test, et al. The study of these aspects should be included in future research.

\section{ACKNOWLEDGEMENTS}

This research was supported by National Basic Research Program of China (973 Program) (Grant No. 2011CB013703), the Fundamental Research Funds for the Central Universities, National Natural Science Foundation of China (Grant NO. 51579227, No.41206075). The financial supports are greatly acknowledged.

\section{REFERENCES}

[1] Shen M, Hu Z, Liu G. Dynamic response and viscous effect analysis of a TLP-type floating wind turbine using a coupled aero-hydromooring dynamic code[J]. Renewable Energy, 2016, 99:800-812.
[2] A. Aubault, M. Alves, A. Sarmento, D. Roddier and A. Peiffer. Modeling of an oscillating water column on the floating foundation WindFloat. In 30th International Conference on Ocean, Offshore and Arctic Engineering, No. OMAE 2011-49014, 2011.

[3] A. Peiffer, D. Roddier, A. Aubault. Design of a point absorber inside the WindFloat structure. In: Proceedings of the 30th International Conference on Ocean, Offshore and Arctic Engineering, Paper no. OMAE2011-49015, Rotterdam, 2011, the Netherlands.

[4] E. E. Bachynski, T. Moan. Point absorber design for a combined wind and wave energy converter on a tension-leg support structure. Proceedings of the ASME 32nd International Conference on Ocean, Offshore and Arctic Engineering, 2013, June 9-14, Nantes, France.

[5] Michailides C., Luan C., Gao, Z., Moan T. Effect of flap type wave energy converters on the response of a semi-submersible wind turbine in operational conditions. In 33th International Conference on Ocean, Offshore and Arctic Engineering, OMAE2014-24065, 2014, June 814, San Francisco, USA..

[6] M. J. Muliawan, M. Karimirad, T. Moan, Z. Gao. STC (Spar-Torus Combination): a combined spar-type floating wind turbine and large point absorber floating wave energy converter-promising and challenging. In: Proceedings of the International Conference on Ocean, Offshore and Arctic Engineering (OMAE) 2012, Rio de Janeiro, Brazil.

[7] M. J. Muliawan, M. Karimirad, T. Moan. Dynamic response and power performance of a combined spar-type floating wind turbine and coaxial floating wave energy converter. Renewable Energy, 2013, 50: 47-57.

[8] M. J. Muliawan, M. Karimirad, Z. Gao, T. Moan. Extreme responses of a combined spar-type floating wind turbine and floating wave energy converter (STC) system with survival modes. Ocean Engineering, 2013, 65: 71-82.

[9] L. Wan, Z. Gao, T. Moan. Experimental and numerical study of hydrodynamic responses of a combined wind and wave energy converter concept in survival modes. Coastla Engineering, 2015, 104:151-169.

[10] L. Wan, Z. Gao, T. Moan., et al. Experimental and numerical comparisons of hydrodynamic responses for a combined wind and wave energy converter concept under operational conditions[J]. Renewable Energy, 2016, 93:87-100.

[11] L. Wan, Z. Gao, T. Moan., et al. Comparative experimental study of the survivability of a combined wind and wave energy converter in two testing facilities[J]. Ocean Engineering, 2016, 111:82-94.

[12] N. X. Ren, Z. Gao, T. Moan. Long-term stochastic dynamic analysis of a combined floating spar-type wind turbine and wave energy converter (STC) system for mooring fatigue damage and power prediction. Proceeding of the 33rd International Conference on Ocean, Offshore and Arctic Engineering, 2014, San Francisco, USA.

[13] N. X. Ren, Z. Gao, T. Moan, L. Wan. Long-term performance estimation of the Spar-Torus-Combination (STC) system with different survival modes. Ocean Engineering, 2015, 108: 716-728.

[14] Wavebob. Available from: www.wavebob.com, 2010.

[15] Jonkman J. M., Butterfield S., Musial W., and Scott G. Definition of a 5-MW reference wind turbine for offshore system development[R]. Golden (CO): National Renewable Energy Laboratory, NREL/TP500-38060, 2007

[16] ANSYS, Inc. ANSYS AQWA User's Manual (Release 13.0), 2010. 